\title{
A Corpus Based Study of Addiction Treatment Manuals
}

\author{
Margaret A. O'Hara ${ }^{1}$ and Cass Dykeman
}

\author{
Oregon State University
}

\section{A Preprint}

\begin{abstract}
Objective: Research indicates that the language used in addiction matters; therefore, the purpose of this study was to investigate whether differences in discursive and psychological processes exist in treatment manuals used for addiction treatment. Method: Using a synchronic corpus linguistic design, twelve-step facilitation, cognitive behavioral therapy, and motivation enhancement therapy manuals from Project MATCH were analyzed using LIWC2015. The log-likelihood ratio test was used to examine if difference in variables exist between the three manuals, with post hoc analysis to further examine differences. Bayesian information criterion was used to measure effect size, which ranged from weak to very strong. Results: Statistically significant differences exist in analytical thinking, authentic, emotional tone, first-person singular pronouns, second-person pronouns, third-person plural pronouns, negative emotion, male, and biological process words. Conclusions: Differences exist in psycholinguistic, linguistic, psychological, and physical processes between TSF, MET, and CBT. The greatest differences across all variables were between TSF and MET. Physical and mental aspects are addressed in TSF, whereas MET focuses on mental aspects. Knowledge of these and other differences support treatment matching for improved client outcomes. Findings of this study may have relevance to clinicians who provide addiction treatment, manual writers, addiction researchers, and clients with addiction issues. Further study of $I$ words, which correlate with truth-telling, versus we words which support community, is suggested.

Keywords: addiction, alcohol use disorder, corpus linguistics, LIWC, treatment manuals
\end{abstract}

1. Correspondence concerning this article should be addressed to Margaret A. O'Hara at oharam@oregonstate.edu 


\title{
A Corpus Based Study of Addiction Treatment Manuals
}

\author{
My drug dealer was a doctor, doctor \\ Had the plug from Big Pharma, Pharma \\ He said that he would heal me, heal me \\ But he only gave me problems, problems \\ My drug dealer was a doctor, doctor \\ Had the plug from Big Pharma, Pharma \\ I think he trying to kill me, kill me \\ He tried to kill me for a dollar, dollar
}

(Macklemore, 2016)

Language is powerful-often lethal. In 1980, a one-paragraph letter published in the New England Journal of Medicine (Porter \& Jick, 1980) was instrumental in fueling the American opiate epidemic. It falsely claimed a low risk of addiction when opiates were prescribed for chronic pain. The publication had no supporting evidence, yet it was referenced in over 600 citations (Leung, Macdonald, Stanbrook, Dhalla, \& Juurlink, 2017). Money talks. However, in 2007, OxyContin manufacturers pled guilty to criminal charges that they misled the medical community, regulators, and the public (Meier, 2007). Overdoses related to prescription opioids accounted for over 200,000 deaths in the United States from 1999 to 2016, with five times higher rates in 2016 compared to 1999 (Seth, Rudd, Noonan, \& Haegerich, 2018). There is no bringing back the sons, daughters, sisters, brothers, mothers, fathers, and friends who were misinformed and crossed the line to fatal addiction. Their lives are lost. There are many who still suffer. How can those who struggle with substance use disorders restore their faith in the research and medical community? What can we learn from the tragic fallacy that was promulgated? Language matters.

The language of addiction matters because rehabilitative treatment is through talk therapy. Outdated terminology does not reflect what is known by scientists about addiction. Hence, there is a "growing movement in the scientific and advocacy community to reframe the language of addiction" (Gordon, 2016, p. 3). Kelly joins others who have called for an examination of the language used in this area (e.g., Dossett, 2017; Kelly, 2017; Kurtz, 2017; McCrady, 1994). Though addiction treatment manuals are often used to guide treatment, their language is unstudied. One study on the language 
in a mindfulness treatment manual for substance-use treatment was located (Collins et al., 2009). The present study of addiction treatment manuals from a large clinical trial (Project MATCH Research Group [PMRG], 1997, 1998) contains analysis of rhetorical and psychological processes, including emotion words. Researchers of a prior study used Project MATCH data and found that there were worse outcomes for clients with comorbid depression whose therapists focused too much on negative emotions (Karno \& Longabaugh, 2003). Other researchers (e.g., Kelly, 2017; Zemore, 2017) questioned the potential role of positive emotions in the addiction recovery process and have called for further exploration, though, to date, "no one has looked into quantifying this" (J. Kelly, personal communication, November 12, 2018). By studying emotion word-use and other variables, this analysis of addiction treatment manuals will fill a knowledge gap. It may add support to the movement to reframe the language of addiction to better serve those who are afflicted.

To provide context for the study, a review of the literature was conducted. Five topics that emerged are addressed. These are: (a) What is manualized treatment? (b) a description of manualized addiction research prior to Project MATCH, (c) a description of Project MATCH and its significance, (d) a description of twelve-step facilitation (TSF), cognitive behavioral therapy (CBT) and motivational enhancement therapy (MET), and (e) representative studies using Linguistic Inquiry and Word Count (LIWC) in addiction research. Once these areas are addressed, the research questions are described.

Manualized treatment refers to psychotherapy that follows a standardized structure, including practices that have been supported by well-controlled research with random assignment. Clinicians stay updated on best practices through professional literature. Whereas journal articles include treatment effects reports, manuals describe in greater depth how to deliver treatment (LeCroy, 2008). Accordingly, the likelihood that practitioners will be able to deliver effective therapies to patients is increased (LeCroy, 2008). Singer and Greeno (2013) stressed that manuals should be written with clinician rather than researcher in mind. As a dissemination tool of evidence-based therapies, treatment manuals have been credited with improving clinical practice while also criticized for imposing impersonal treatment that is not practical or reflective of real- 
world issues (Godley, White, Diamond, Passetti, \& Titus, 2001). Godley et al. (2001) studied 19 clinicians who used manualized treatment for problem use of cannabis. Almost all reported positive experiences and identified ease of use, structure, and focus as reasons why.

Treatment manuals are relatively new in the counseling field. They have been studied in psychotherapy research only since the 1960s (Duncan, Nicol, \& Ager, 2004). The first identified treatment manual was Paul's (1966) dissertation based on the procedural elements of systematic desensitization provided by Wolpe (1958). Treatment manuals marked the advent of manualized treatment, though addiction treatment lagged. The Minnesota Model (Cook, 1988) was the traditional American approach that dominated addiction treatment in spite of a lack of research to support its effectiveness.

\section{Project MATCH (Matching Alcohol Treatment to Client} Heterogeneity) was a large, multisite clinical trial that sought to find ways to match individuals with treatment that best suited them (PMRG, 1997, 1998). The 806 clients in five outpatient facilities were randomly assigned to either TSF or one of two theoretically-driven, highly-studied therapies: CBT and MET. The researchers found few differences in outcomes between the three treatment approaches; however, results garnered respect for TSF, the least-studied approach, and indirectly for Alcoholics Anonymous (AA) as the main goal of TSF is to help clients work the 12 steps. Results showed that clients achieved higher levels of overall abstinence and attended more 12-step meetings when they participated in TSF. At one-year posttreatment, more than double the number of participants remained abstinent, and at the three-year mark approximately one-third more were abstinent (Tonigan, Connors, \& Miller, 2003).

A three-year follow-up study was conducted (Longabaugh, Wirtz, Zweben, \& Stout, 1998). Results showed 50\% higher abstinence rates in the prior 90 days for the TSF group when compared with CBT. The researchers concluded that, for those whose networks supported drinking, TSF may be the treatment of choice and that regardless of the therapeutic approach AA should be considered. The results of Project MATCH (PMRG, 1997, 1998) were surprising and significant. Prior to Project 
MATCH, research on AA and professionally led treatments that support AA, such as TSF, were not considered to be methodologically sound.

There exist a number of interventions that facilitate engagement in AA and the 12-step recovery process. Common features include education and discussion about 12-step groups, the nature of meetings and what one can expect, and systemic encouragement to participate (Kelly et al., 2016). The 12-step facilitative intervention used in Project MATCH (PMRG, 1997, 1998) was TSF (Nowinski, Baker, \& Carroll, 1992). It is a manually-guided intervention based on the emotional, behavioral, cognitive, and spiritual principles of AA. The aim is to facilitate early recovery through guidance with the beginning steps. The first session covers the disease concept, surrender process, and acceptance of total abstinence. Developed for individual counseling for those with alcohol use disorder (AUD), it has been adapted for use in groups (Brown, Seraganian, Tremblay, \& Annis, 2002a, 2002b) and to address other substances (Baker, 1998; Carroll et al., 2000).

Motivation enhancement therapy (Miller, Zweben, DiClemente, \& Rychtarik, 1992) is a manualized treatment developed for use in research (PMRG, 1997, 1998). MET combined adaptations of an intervention called the "Drinker's Checkup" ([DCU]; Miller \& Sovereign, 1989; Miller, Sovereign, \& Krege, 1988) and motivational interviewing ([MI]; Miller \& Rollnick, 1991, 2002). The DCU was an in-depth assessment of alcohol use and related problems. Increased help-seeking was the expected outcome; however, DCU intervention in and of itself triggered motivation for change. Motivational interviewing is a brief, client-centered intervention and is evidence-based with tested validity and reliability (Madson \& Campbell, 2006). Developed to address AUD, MI has shown beneficial effects across a wide range of problems. Motivational interviewing may be used with other counseling approaches as it was developed as a tool to address and resolve ambivalence in the change process. Motivational interviewing has shown effectiveness when conducted by a broad range of clinicians and with diverse populations.

Cognitive behavior therapy, also referred to as cognitive therapy, was developed in the 1960s by Aaron T. Beck (2005). The theory behind is that the way situations are perceived affects the way one feels about them. This therapeutic approach is used to assist individuals with identifying 
underlying thinking patterns, challenging distortions, and replacing them with healthier thoughts which result in changed behaviors. For example, when cravings are present, clients learn to respond in ways other than drinking, such as noticing how one rationalizes drinking, challenging those thoughts, and replacing them with thoughts that support relapse prevention. Information is conveyed in a lecture format in order to teach skills. The CBT intervention in Project MATCH (PMRG, 1997, 1998) followed a treatment manual developed by Kadden et al. (1992).

A review of the growing body of literature that features LIWC (Pennebaker, Boyd, Jordan, \& Blackburn, 2015) as a methodology instrument used to examine addiction produced a representative sample of articles. A Journal of Studies on Alcohol and Drugs article by Hancock, Talley, Bohanek, Iserman, and Ireland (2018) covered women's ambiguity of sexual orientation, with results showing increased AUD risk when language was aversively focused on self. The Psychology of Addictive Behavior published a language analysis study (Collins, et al., 2009) that compared a mindfulness-based treatment manual to the Big Book, the original text of AA (Wilson, 2001). Support for clinical use of mindfulness language to prevent relapse was found. The journal Substance Abuse also published a linguistic analysis study by Liehr et al. (2010) on mindfulness and relapse prevention. Though significant differences were not found, the authors noted that the intervention group used less negative emotion words for all data points. Also, both groups studied saw a decrease in anxiety and negative emotion words and an increase in positive emotion words. This finding adds knowledge to the literature base on negative and positive emotions in the recovery process (e.g., Folkman, 2008; Kelly, 2017; Keyes, 2007; McHugh, Kaufman, Frost, Fitzmaurice, \& Weiss, 2013; Serafini, Malin-Mayor, Nich, Hunkele, \& Carroll, 2016; Vaillant, 2008; Zemore, 2017). Ding, Bickel, and Pan (2017) studied social media, using data from myPersonality project (Kosinski, Matz, Gosling, Popov, \& Stillwell, 2015). They found a negative correlation for drug use with first-person plural pronouns and positive emotion words and were surprised to find that for alcohol use there was a negative correlation with negative emotions. Finally, an article by Lord, Sheng, Imel, Baer, and Atkins (2015) that used LIWC methodology (Pennebaker et al., 2015) to study language used in MI (Miller \& Rollnick, 1991, 2002) found implications for training MI practitioners. 
Given the aforementioned gaps and needs, three research questions were developed to guide the present study on the Project MATCH (PMRG, 1997, 1998) treatment manuals. The first research question was: Do differences in the level of broad psycholinguistic processes exist among the Project MATCH treatment manuals? The second research question was: Do differences in specific linguistic categories exist among Project MATCH treatment manuals? The third research question was: Do differences in specific psychological and physical processes exist among Project MATCH treatment manuals?

\section{Design}

\section{Method}

This study employed a synchronic corpus linguistic design (Weisser, 2016). The corpora were drawn from the treatment manuals used in Project MATCH (PMRG, 1997, 1998). The treatment manuals studied were TSF, CBT, and MET. The unit of analysis was individual words (Gabrielatos, 2018). The variables were broad psycholinguistic, linguistic, psychological, and physical processes.

\section{Corpora}

Register and source. The register was addiction treatment manuals. The source was the three Project MATCH manuals (PMRG, 1997, 1998). Each manual formed a corpus of the corpora. All manuals were publicly available full-text.

Construction. The file for each corpus was reviewed closely and cleaned according to LIWC2015 manual (Pennebaker et al., 2015) instructions. Charts were removed as LIWC2015 does not recognize them. Spelling errors were corrected and hyphens that appeared in the document but not in the original text were removed. Cover pages, acknowledgements, list of contributors, recommended readings, references, and appendices were removed. The forward, preface, contents, and introduction sections were included for all three manuals. Additionally, in TSF, the overview, caveats, and critical conditions section, as well as the section that explains the treatment manual was included. In MET, sections on clinical 
considerations, practical strategies, structuring the MET session, and dealing with special populations were included. In CBT, the overview, core session, and elective session sections were included.

\section{Measures}

Overview. The first four variables listed are summary variables, scaled from 0 to 100. Higher scores indicate higher degrees of variables. Each is a population-normed, composite variable combining several LIWC2015 categories that reflect empirically-based constructs. The specific algorithms are proprietary and therefore are not publicly available. The remaining variables were reported as a percentage of total words.

Pennebaker, Boyd, et al. (2015) reported acceptable validity and reliability for all of the measures below.

Analytic. Analytic is a variable that measures logical, formal, and hierarchal thinking patterns (Pennebaker, Chung, Frazee, Lavergne, \& Beaver, 2014). High scores reflect this pattern, whereas lower scores suggest an informal, narrative, personal, here-and-now style (Pennebaker, Booth, Boyd, \& Francis, 2015).

Clout. Clout is a variable that measures language indicative of social dominance and leadership (Drouin, Boyd, Hancock, \& James, 2017). When one is in a position of authority, conveys high expertise, and communicates with confidence, a specific, consistent linguistic pattern of several LIWC2015 variables, including pronoun use, is seen. (Kacewicz, Pennebaker, Davis, Jeon, \& Graesser, 2014). High scores reflect this pattern, whereas lower scores reflect an anxious, humble, or tentative style (Pennebaker, Booth et al., 2015).

Authentic. Authentic is a scale that combines scores on a number of variables. Higher scores are indicative of honest (versus deceptive) communication and reflect more authentic and open language (Pennebaker, Booth et al., 2015). It is based on research that identified how word patterns differ when subjects told the truth compared to when they were lying (Newman, Pennebaker, Berry, \& Richards, 2003; Pennebaker, 2011). When being dishonest, people tend to reference themselves less often, use 
more negative emotions words, and use simpler language (Newman et al., 2003).

Tone. Tone combines the positive emotion and negative emotion variables in one summary variable (Cohn, Mehl, \& Pennebaker, 2004). A linguistic style that is emotionally positive would have higher scores, whereas lower scores reflect sadness, anxiety, or hostility (Pennebaker, Booth et al., 2015).

First-person singular pronoun. First-person singular pronouns are used in place of a noun when there is personal reference to the speaker or writer. Examples include $I$ and mine.

Third-person singular pronoun. Third-person singular pronouns are used in place of a noun when there is reference to a person, animal, or thing other than the speaker or writer and reader or listener. Examples include she and him.

Second-person pronoun. Second-person pronouns are singular or plural and are used in place of a noun to address the reader or listener. Examples include you and your.

First-person plural pronoun. First-person pronouns are used in place of a noun when speaking or writing to a group that includes the speaker or writer. Examples include we and us.

Third-person plural pronoun. Third-person pronouns are used in place of noun when there is reference to people, animals, or things other than the speaker or writer and reader or listener. Examples include they and their.

Impersonal pronoun. Impersonal pronouns do not refer to a particular person, animal, or thing. Examples include it and those.

Positive emotion. Positive emotions are defined as intense and pleasurable mental experiences (Cabanac, 2002) and short-lived "multicomponent response tendencies" (Fredrickson, 2001, p. 218). Examples include love and nice. 
Negative emotion. Negative emotions are usually unpleasant emotions that are evoked in individuals to express negative feelings towards an event or person. Examples include hurt, ugly, and nasty.

Female reference. Female references include nouns and pronouns. Examples include her and mom.

Male reference. Male references include nouns and pronouns. Examples include his and boy.

Biological process. Biological process words refer to the life processes of living organisms. Examples include eat and pain.

\section{Apparatus}

The text analysis software used to analyze the data for this study was the Linguistic Inquiry and Word Count 2015 (LIWC2015) program (Pennebaker, Booth et al., 2015). Text files were analyzed yielding scores for approximately 90 output variables. Each data record begins with the file name, word count, and four summary language variables (i.e., analytic, clout, authentic, and tone). Next, a general descriptor variable - words per sentence - is listed. These six variables were not reported as percentages. The remaining variables were all calculated as a percentage of the total words in the file. These included two additional general descriptor variables (i.e., percentage of words containing greater than six letters and percentage of words captured by the dictionary), 21 standard linguistic categories (e.g., percentage of articles, pronouns, and auxiliary verbs), 41 word categories for psychological constructs (e.g., cognition and affect), six personal concern variables (e.g., home, work, and leisure activities), five paralinguistic

categories (e.g., fillers and non-fluencies), and 12 punctuation variables (e.g., commas and periods).

\section{Data Analysis}

To answer the research questions, the log-likelihood ratio test (LL) was used to examine if differences exist between the three manuals (Brezina, 2018). When an LL result was significant, post hoc analyses were 
conducted to examine difference between specific corpora. The post hoc testing procedure is identical to the overall log-likelihood ratio test, except word frequencies are regrouped to focus on specific corpora. If a category variable was found to be significant, three additional post hoc LL tests were conducted. To control the probability of falsely rejecting at least one null hypothesis in a family of $m$ hypotheses with an overall significance level of $\alpha=0.05$, the Bonferroni correction was applied such that each hypothesis was tested at an adjusted significance level of $\alpha_{\alpha}=\alpha / m$. The Bayesian information criterion (BIC) was used to measure effect size. Positive BIC values measure the strength of evidence against the null hypothesis; negative BIC values measure the strength of evidence in favor of the null hypothesis. The following descriptors for the absolute value of BIC were used: not worth more than a bare mention (0-2), positive evidence (2-6), strong evidence (6-10), and very strong evidence (>10) (Wilson, 2013). All analyses were conducted using $\mathrm{R}$.

\section{Results}

\section{Research Question 1 (Broad Psycholinguistic Processes)}

Differences in four broad psycholinguistic processes among the manuals were examined $(d f=2, \alpha \mathrm{a}=0.05 / 4=0.0125, c v=8.76)$. See Table 1 at the end of this chapter for results of significance testing for these elements. Post hoc testing for broad psycholinguistic processes ( $d f=1$, $\alpha \mathrm{a}=0.05 / 12=0.0042, c v=8.21$ ) was conducted. See Table 2 at the end of this chapter for results of post hoc testing.

\section{Research Question 2 (Linguistic Processes)}

Difference in six linguistic processes among the manuals were examined $(d f=2, \alpha \mathrm{a}=0.05 / 6=0.0083, c v=9.57)$. See Table 1 for results of significance testing for these elements. Post hoc testing for linguistic processes $(d f=1, \alpha \mathrm{a}=0.05 / 15=0.0033, c v=8.62)$ was conducted. See Table 2 for results of post hoc testing.

\section{Research Question 3 (Psychological and Physical Processes)}

Differences in five psychological/physical processes among the manuals were examined $(d f=2, \alpha a=0.05 / 5=0.01, c v=9.21)$. See Table 1 for results of significance testing for these elements. Post hoc testing for 
psychological/ physical processes $(d f=1, \alpha \mathrm{a}=0.05 / 9=0.0056, c v=7.69)$ was conducted. See Table 2 for results of post hoc testing.

\section{Discussion}

This study sought to explore word usage of treatment manuals for AUD and used manuals from Project MATCH (PMRG, 1997, 1998). Using the broad psycholinguistic categories of analytic, clout, authentic, and tone words, the first research question examined whether differences exist in the Project MATCH treatment manuals. Using the linguistic process categories of first-person singular pronoun, third-person singular pronoun, secondperson pronoun, first-person plural pronoun, third-person plural pronoun, and impersonal pronouns, the second research question examined whether differences exist among Project MATCH treatment manuals. Using the psychological process categories of positive emotion and negative emotion

and physical process categories of female, male, and biological processes, the third research question examined whether differences exist in Project MATCH treatment manuals.

The first research question was related to the broad psycholinguistic categories. For analytic scores, TSF had higher standard scores, and MET had lower scores than expected. There are two probable reasons for the obtained results for analytic scores. One possible reason is that the language in MET is informal, whereas TSF language is more formal. An alternative explanation is that TSF, as a step-by-step approach (Nowinski et al., 1992), receives higher standard scores for being logical and hierarchal (Pennebaker et al., 2014), whereas MET does not attempt to provide such step-by-step guidance (Miller et al., 1992). Between the former and the latter explanations, the latter is most likely because TSF has a logical progression with its step-by-step approach.

For authentic, TSF was lower, and MET and CBT were higher than expected. There are three probable reasons for the obtained results for authentic. One possible reason may be that this LIWC2015 variable is a standard score derived from deception research of individuals (Newman et al., 2003; Pennebaker, 2011) and may not apply to texts such as treatment manuals. Another explanation for the obtained results may be due to the fact that the LIWC2015 composite variable of authentic was derived from research indicating that $I$ words are associated with truth-telling, which is 
an indication that one is speaking from the heart (Jordan \& Pennebaker, 2017). TSF is based on AA, which prefers we words over $I$ words as a means to convey a sense of community, not because of dishonesty. A third explanation may be that TSF reflects less openness in public discourse, as was characteristic of the era in which AA was founded (Klein, 2018). TSF is closely aligned with AA, which was written in the 1930s when public discourse was less open than today, a trend described in a Pennebaker interview (Sutton, 2017). Bulkeley and Graves (2018) point out that in LIWC2015, the more a writer filters what is being said for their audience, the lower the authentic score and vice versa. Between the three explanations, the third is most likely because TSF has its basis in AA, whose literature was written long before the other manuals, during an era of less openness and more filtering.

For tone, TSF and CBT had lower scores and MET had higher scores than expected. There are two plausible reasons for these results. One possible reason is that MET is a therapy that leans positive in terms of emotion as MET is based on motivational psychology (Miller et al., 1992). An alternative explanation is that TSF and CBT are deficit-model therapies that focus on denial (Kadden et al.,1992; Nowinski et al., 1992). Between the former and the latter explanations, the latter is most likely because TSF and CBT address denial, and typically treatment is initiated by some presenting problem; hence, low scores for tone words were not unexpected.

The second research question was related to the linguistic categories of pronoun usage. For first-person singular pronouns, use was lower in TSF and higher in MET and CBT. One possible reason is that the individual perspective is not considered in TSF, whereas it is valued in MET and CBT. An alternative explanation is that TSF is highly aligned with AA, which as far back as the 1930s, stressed the community approach and use of we instead of $I$ (Anonymous, 2010), whereas this approach has not been stressed in MET or CBT. Between the former and the latter explanations, the latter is most likely because the individual perspective is supported and safeguarded in TSF and AA with emphasis placed on supporting newcomers and helping them form their own conceptualizations, including personal experiences of spirituality and surrender (Alcoholics Anonymous, 1981; Wilson, 2001). Additionally, the intentional change to we language is welldocumented in AA history (Anonymous, 2010). 
Similarly, there is a decreased rate of second-person pronouns in TSF and an increased use in MET. One possible reason is that in TSF there is less distinction between a TSF trainer, therapist, and client, hence, less use of you pronouns with a greater emphasis on we, whereas in MET there is a hierarchy with greater distinction between MET trainers, therapists, and clients. MET is a more research-based and clinically based approach (Kelly, 2017), which may be inherently more hierarchal, whereas TSF evolved from more egalitarian 12-step community groups (Nowinski et al., 1992). An alternative explanation for the decreased rate of second-person pronouns is that in TSF, therapists are opposed to prescribing behavior (Nowinski et al., 1992), similar to AA, which again, as far back as the 1930s, stressed the need to avoid telling people what to do (Alcoholics Anonymous, 1981; Anonymous, 2010; Wilson, 2001), whereas MET is a directive approach in which therapists are encouraged to give advice (Miller et al., 1992). Between the former and the latter explanations, the latter is most likely because giving advice entails more use of second-person pronouns.

There is an increased use of third-person plural pronouns in TSF and a decreased use in MET. One possible reason is that third-person pronouns are being used to differentiate and sometimes create distance between us (i.e., healthy clinicians) and them (i.e., sick clients). A second explanation may be that the writers of TSF were aware of the health benefits of perspective switching, which refers to pronoun use variation (Campbell \& Pennebaker, 2003; Jin, 2005; Seih, Lin, Huang, Peng, and Huang, 2008), and specifically, the self-distancing that the third-person perspective allows (Kross, Ayduk, \& Mischel, 2005). A third explanation is that, although supportive of AA, TSF is not AA; therefore, use of third-person plural pronouns in the TSF manual may be used when referring to AA, its members, its practices, and its principles. The third is the most likely explanation due to a lack of research to support the first two explanations. Many practitioners who are drawn to TSF are themselves "wounded healers" (White, 2011) and have empathy for what their clients experience. Their background might preclude them from stressing such a differentiation. Furthermore, research on perspective switching came after Project MATCH (PMRG, 1997, 1998). 
The third research question was related to psychological/physical categories. The only difference found with emotion words was that there were fewer than expected negative emotion words in MET. One possible reason is that in MET the expression of negative emotions is denied. An alternative explanation is that compared to TSF and CBT, in MET there is less emphasis on negative emotions and consequences and more emphasis on the change process. Between the former and the latter explanations, the latter is most likely because MET seeks to enhance motivation and focus on the change process (Miller et al., 1992). Miller and Sanchez (1994) developed a framework within MET known as FRAMES (Feedback, Responsibility, Advice, Menu of options, Empathy, Self-efficacy) that includes elements of brief interventions that induce change, including support for self-efficacy and optimism (Miller et al., 1992).

For male words, use was lower in CBT and higher in TSF. One possible reason might be that CBT is a more feminine approach, and TSF is a more masculine approach. An alternative explanation is that CBT was developed for more universal use with many clients without regard to sex or gender; whereas TSF had its basis in AA with AA literature written decades ago and representative of the higher prevalence of men coming forward for help at that time (Maxwell, 1982; White, 1998). Between the former and the latter explanations, the latter is most likely because there is no research to support the former, whereas the fact that AA literature reflects the high prevalence rate of males with AUD seeking help at the time of publication has been referenced (Maxwell, 1982; White, 1998). Additionally, because AA was founded by men, the effectiveness of TSF for men was predicted to be higher than for women in Project MATCH (PMRG, 1997, 1998).

The biological process words were higher in TSF and lower in MET. One possible reason is that TSF is more descriptive of life processes compared to MET. An alternative explanation is that TSF is based on AA, which not only stresses mental, but also physical aspects of AUD (Alcoholics Anonymous, 1981; Anonymous, 2010; Nowinski et al., 1992; Wilson, 2001), whereas MET focuses only on mental aspects. Between the former and the latter explanations, the latter is most likely because physical manifestations of AUD receive more focus in TSF and AA than in MET. 
Although results of this study advanced knowledge of the language of addiction, there were limitations. One is that the treatment manuals were written by different authors. Results of the analysis could be related to their different writing styles rather than differences in the treatment modalities. A future study might inform one writer, who is unaffiliated with any of the approaches, about the workings of each model so that the different writing styles would not confound results. A second limitation is that the LIWC2015 scores for analytic, clout, authentic, and tone do not reflect actual usage, but instead rely on a nontransparent LIWC2015 algorithm derived from large comparison samples. Outcome scores for analytic, clout, authentic, and tone show where each standard score fell on a normal curve based on prior research. The non-transparency of the algorithm is a limitation for the researcher as it creates an element of uncertainty. In terms of external validity, the results from this study were specific to the texts analyzed and therefore they are not generalizable.

The literature presented has shown that the language of addiction matters. There are several implications of the current study for counseling practitioners. First, the high analytic results add to the steadily increasing evidence base for TSF, which, prior to a call for research (Institute of Medicine, 1990), was frowned upon for not having scientific support. Clinicians who provide or refer clients to TSF treatment have one more study that supports its efficacy. Additionally, the analytic results may mean that compared to MET, TSF may provide more benefit to a client who needs step-by-step guidance. Second, the higher MET results and lower TSF results for second-person pronouns, may inform clinicians that MET is a directive approach while TSF is non-directive. Knowledge of this difference may be beneficial in matching clients to treatments that resonate with them. The higher TSF results and lower MET results for biological process words, may inform clinicians that TSF takes a mind, body, spirit approach; whereas MET is based in motivation psychology with little emphasis on physical or spiritual aspects of addiction. This differentiation may prove helpful for client matching. Finally, where CBT had the least variation across variables, the results for TSF and MET indicate stark differences for many categories: analytic, authentic, tone, first-person singular, second-person, third-person plural, and biological process words. Hence, if a client does not respond well to one of these approaches, it may be beneficial to switch to the other treatment approach. Broader 
implications include TSF and AA consideration of how the overuse of male language impacts females as well as other gendered individuals. This study would add to the research on gender differences in AA (Kelly, 2013).

Several implications for researchers were drawn from this study. First, this research is the first study to examine linguistic components of addiction treatment manuals. Findings may have relevance to clinicians who provide treatment for SUDs, writers of manuals, researchers who examine and develop treatment approaches, and clients with SUDs. Research demonstrates that differences exist in the broad psycholinguistic, specific linguistic, and psychological and physical process words used in the treatment manuals studied. Future research may help differentiate when texts with different authentic scores vary due to filtering and the degree of openness of the era in which they were written versus deception and dishonesty. It may be interesting to examine use of $I$ words, which correlate with truth-telling, versus use of we words, which support community, when authors have a choice in whether to communicate from the first-person singular or first-person plural perspective. TSF and CBT had less tone, whereas MET had higher tone and less negative emotions. Given the aforementioned interest in the role of positive and negative emotions in addiction treatment, further research is warranted. 


\section{References}

Alcoholics Anonymous. (1981). Twelve steps and twelve traditions. New York, NY: Alcoholics Anonymous World Services.

Anonymous. (2010). The book that started it all: The original working manuscript of Alcoholics Anonymous. Center City, MN: Hazelden.

Baker, S. M. (1998). Twelve step facilitation therapy for drug abuse and dependence. New Haven, CT: Yale University Professional Development Committee.

Beck, A. T. (2005). The current state of cognitive therapy: A 40-year retrospective. Archives of General Psychiatry, 62, 953-959. http://doi.org/10.1037/arc0000014

Brezina, V. (2018). Statistics in corpus linguistics: A practical guide. Cambridge, UK: Cambridge University Press.

Brown, T. G., Seraganian, P., Tremblay, J., \& Annis, H. (2002a). Matching substance abuse aftercare treatments to client characteristics. Addictive Behaviors, 27, 585-604. https://doi.org/10.1016/s03064603(01)00195-2

Brown, T. G., Seraganian, P., Tremblay, J., \& Annis, H. (2002b). Process and outcome changes with relapse prevention versus 12-Step aftercare programs for substance abusers. Addiction, 97, 677-689. https://doi.org/10.1046/j.1360-0443.2002.00101.x

Bulkeley, K., \& Graves, M. (2018). Using the LIWC program to study dreams. Dreaming, 28, 43-58. https://doi.org/10.1037/drm0000071

Cabanac, M. (2002). What is emotion? Behavioural Processes, 60, 69-83 https://doi.org/10.1016/S0376-6357(02)00078-5

Campbell, R. S., \& Pennebaker, J. W. (2003). The secret life of pronouns: Flexibility in writing style and physical health. Psychological Science, 14, 60-65. https://doi.org/10.1111/1467-9280.01419

Carroll, K. M., Nich, C., Ball, S. A., McCance, E., Frankforter, T. L., \& Rounsaville, B. J. (2000). One year follow up of disulfiram and psychotherapy for cocaine alcohol users: Sustained effects of treatment. Addiction, 95, 1335-1349. https://doi.org/10.1046/j.13600443.2000.95913355.x

Cohn, M. A., Mehl, M. R., \& Pennebaker, J. W. (2004). Linguistic markers of psychological change surrounding September 11, 2001. Psychological Science, 15, 687-693. https://doi.org/10.1111/j.09567976.2004.00741.x 
Collins, S. E., Chawla, N., Hsu, S. H., Grow, J., Otto, J. M., \& Marlatt, G. A. (2009). Language-based measures of mindfulness: Initial validity and clinical utility. Psychology of Addictive Behaviors, 23, 743. https://doi.org/10.1037/a0017579

Cook, C. C. H. (1988). The Minnesota Model in the management of drug and alcohol dependency: Miracle, method or myth? Part I. The philosophy and the programme. British Journal of Addiction, 83, 625-634. https://doi.org/10.1111/j.1360-0443.1988.tb02591.x

Ding, T., Bickel, W. K., \& Pan, S. (2017). Multi-view unsupervised user feature embedding for social media-based substance use prediction. In Proceedings of the 2017 Conference on Empirical Methods in Natural Language Processing (pp. 2275-2284). https://doi.org/10.18653/v1/d17-1241

Dossett, W. (2017). A daily reprieve contingent on the maintenance of our spiritual condition. Addiction, 112, 942-943. https://doi.org/10.1111/add.13731

Drouin, M., Boyd, R. L., Hancock, J. T., \& James, A. (2017). Linguistic analysis of chat transcripts from child predator undercover sex stings. The Journal of Forensic Psychiatry \& Psychology, 28, 437-457. https://doi.org/10.1080/14789949.2017.1291707

Duncan, E. A., Nicol, M. M., \& Ager, A. (2004). Factors that constitute a good cognitive behavioural treatment manual: A Delphi study. Behavioural and Cognitive Psychotherapy, 32, 199-213. https://doi.org/10.1017/s135246580400116x

Folkman, S. (2008). The case for positive emotions in the stress process. Anxiety, Stress, and Coping, 21, 3-14. https://doi.org/10.1080/10615800701740457

Fredrickson, B. L. (2001). The role of positive emotions in positive psychology: The broaden-and-build theory of positive emotions. American Psychologist, 56, 218-226. https://doi.org/10.1037//0003066x.56.3.218

Gabrielatos, C. (2018). Keyness Analysis: Nature, metrics and techniques. In C. Taylor \& A. Marchi (Eds.), Corpus approaches to discourse: $A$ critical review (pp. 225-258). Oxford, UK: Routledge.

Godley, S. H., White, W. L., Diamond, G., Passetti, L., \& Titus, J. C. (2001). Therapist reactions to manual-guided therapies for the treatment of adolescent marijuana users. Clinical Psychology: Science and Practice, 8, 405-417. https://doi.org/10.1093/clipsy.8.4.405 
Gordon, E. (2016, June). Reframing the language of addiction: Researcher pushes to strike the term 'abuse.' Side Effects. Retrieved from http://www.sideeffectspublicmedia.org/post/reframing-languageaddiction-researcher-pushes-strike-term-abuse

Hancock, D. W., Talley, A. E., Bohanek, J., Iserman, M. D., \& Ireland, M. (2018). Sexual orientation self-concept ambiguity and alcohol use disorder symptomology: The roles of motivated psychological distancing and drinking to cope. Journal of Studies on Alcohol and Drugs, 79, 96-101. https://doi.org/10.15288/jsad.2017.79.96

Institute of Medicine. (1990). Broadening the base of treatment for alcohol problems. Washington DC: The National Academies Press.

Jin, S. R. (2005). The dialectical effect of psychological displacement: A narrative analysis. Taipei, China: National Science Council.

Jordan, K. N., \& Pennebaker, J. W. (2017). Trump's inaugural address. Retrieved from https://wordwatchers.wordpress.com/tag/authentic/

Kacewicz, E., Pennebaker, J. W., Davis, M., Jeon, M., \& Graesser, A. C. (2014). Pronoun use reflects standings in social hierarchies. Journal of Language and Social Psychology, 33, 125-143. https://doi.org/10.1177/0261927x13502654

Kadden, R., Carroll, K., Donovan, D., Cooney, N., Monti, P., Abrams, D., . . . \& Hester, R. (1992). Cognitive-behavioral coping skills therapy manual (Vol. 3). Rockville, MD: National Institute on Alcohol Abuse and Alcoholism.

Karno, M. P., \& Longabaugh, R. (2003). Patient depressive symptoms and therapist focus on emotional material: A new look at Project MATCH. Journal of Studies on Alcohol, 64, 607-615. https://doi.org/10.15288/jsa.2003.64.607

Kelly, J. F. (2013). Does Alcoholics Anonymous work differently for men and women? A moderated multiple-mediation analysis in a large clinical sample. Drug and Alcohol Dependence, 130, 186-193.

Kelly, J. F. (2017). Is Alcoholics Anonymous religious, spiritual, neither? Findings from 25 years of mechanisms of behavior change research. Addiction, 112, 929-936. https://doi.org/10.1111/add.13590

Kelly, J. F., Yeterian, J. D., Cristello, J. V., Kaminer, Y., Kahler, C. W., \& Timko, C. (2016). Developing and testing twelve-step facilitation for adolescents with substance use disorder: Manual development and preliminary outcomes. Substance Abuse: Research and Treatment, 10, 55-64. https://doi.org/10.4137/SART.S39635 
Keyes, C. L. M. (2007). Promoting and protecting mental health as flourishing: A complementary strategy for improving national mental health. American Psychologist, 62, 95-108. https://doi.org/10.1037/0003-066x.62.2.95

Klein, T. (2018). The book that started it all: The original working manuscript of Alcoholics Anonymous. Psych Central. Retrieved from https://psychcentral.com/lib/the-book-that-started-it-all-the-originalworking-manuscript-of-alcoholics-anonymous/

Kosinski, M., Matz, S. C., Gosling, S. D., Popov, V., \& Stillwell, D. (2015). Facebook as a research tool for the social sciences: Opportunities, challenges, ethical considerations, and practical guidelines. American Psychologist, 70, 543-556. https://doi.org/10.1037/a0039210

Kross, E., Ayduk, O., \& Mischel, W. (2005). When asking "why" does not hurt: Distinguishing rumination from reflective processing of negative emotions. Psychological Science, 16, 709-715.

https://doi.org/10.1111/j.1467-9280.2005.01600.x

Kurtz, L. F. (2017). The recovery community as a location for secular spirituality. Addiction, 112, 939-940. https://doi.org/10.1111/add.13716

LeCroy, C. W. (Ed.). (2008). Handbook of evidence-based treatment manuals for children and adolescents ( $2^{\text {nd }}$ ed.). New York, NY: Oxford University Press.

Leung, P. T., Macdonald, E. M., Stanbrook, M. B., Dhalla, I. A., \& Juurlink, D. N. (2017). A 1980 letter on the risk of opioid addiction. New England Journal of Medicine, 376, 2194-2195. https://doi.org/10.1056/nejmc1700150

Liehr, P., Marcus, M. T., Carroll, D., Granmayeh, L. K., Cron, S. G., \& Pennebaker, J. W. (2010). Linguistic analysis to assess the effect of a mindfulness intervention on self-change for adults in substance use recovery. Substance Abuse, 31, 79-85. https://doi.org/10.1080/08897071003641271

Longabaugh, R., Wirtz, P. W., Zweben, A., \& Stout, R. L. (1998). Network support for drinking, Alcoholics Anonymous and long-term matching effects. Addiction, 93, 1313-1333. https://doi.org/10.1046/j.13600443.1998.93913133.x

Lord, S. P., Sheng, E., Imel, Z. E., Baer, J., \& Atkins, D. C. (2015). More than reflections: Empathy in motivational interviewing includes 
language style synchrony between therapist and client. Behavior Therapy, 46, 296-303. https://doi.org/10.1016/j.beth.2014.11.002 Macklemore (Artist), Deboo, A. (Featured Artist). (2016). Drug Dealer. On Drug Dealer. Seattle, WA: Macklemore.

Madson, M. B., \& Campbell, T. C. (2006). Measures of fidelity in motivational enhancement: A systemic review. Journal of Substance Abuse Treatment, 31, 67-73.

https://doi.org/10.1016/j.jsat.2006.03.010

Maxwell, M. (1982). Alcoholics Anonymous. In E. Gomberg, H. White, \& J. Carpenter (Eds.), Alcohol, science and society revisited (pp. 295305). Ann Arbor, MI: The University of Michigan Press.

McHugh, R. K., Kaufman, J. S., Frost, K. H., Fitzmaurice, G. M., \& Weiss, R. D. (2013). Positive affect and stress reactivity in alcoholdependent outpatients. Journal of Studies on Alcohol and Drugs, 74, 152-157. https://doi.org/10.15288/jsad.2013.74.152

Meier, B. (2007). In guilty plea, OxyContin maker to pay $\$ 600$ million. New York Times. Retrieved from https://www.nytimes.com/2007/05/10/business/11drug-web.html

Miller, W. R., \& Rollnick, S. (1991). Motivational interviewing: Preparing people to change addictive behavior. New York, NY: Guilford Press.

Miller, W. R., \& Rollnick, S. (2002). Motivational interviewing: Preparing people for change ( $2^{\text {nd }}$ ed.). New York, NY: Guilford Press.

Miller, W. R., \& Sanchez, V. C. (1994). Motivating young adults for treatment and lifestyle change. In G. S. Howard \& P. E. Nathan (Eds.), Alcohol use and misuse by young adults (pp. 55-81). Notre Dame, IN: University of Notre Dame Press.

Miller, W. R., \& Sovereign, R. G. (1989). The check-up: A model for early intervention in addictive behaviors. In T. Loberg, W. R. Miller, P. E. Nathan, \& G. A. Marlatt (Eds.), Addictive behaviors: Prevention and early intervention (pp. 219-231). Amsterdam, The Netherlands: Swets \& Zeitlinger.

Miller, W. R., Sovereign, R. G., \& Krege, B. (1988). Motivational interviewing with problem drinkers: II. The Drinker's Check-up as a preventive intervention. Behavioral Psychotherapy, 16, 251-268. https://doi.org/10.1017/s0141347300014129

Miller, W. R., Zweben, A., DiClemente, C., \& Rychtarik R. (1992). Motivational Enhancement Therapy Manual: A clinical research guide for therapists treating individuals with alcohol abuse and 
dependence, Project MATCH monograph series (Vol. 2), DHHS Pub. No. (ADM) 92-1894.

Newman, M. L., Pennebaker, J. W., Berry, D. S., \& Richards, J. M. (2003). Lying words: Predicting deception from linguistic styles. Personality and Social Psychology Bulletin, 29, 665-675.

https://doi.org/10.1177/0146167203029005010

Nowinski, J., Baker, S., \& Carroll, K. (1992). Twelve step facilitation therapy manual: $A$ clinical research guide for therapists treating individuals with alcohol abuse and dependence (Vol. 1). Rockville, MD: National Institute on Alcohol Abuse and Alcoholism.

Paul, G. L. (1966). Insight vs. desensitization in psychotherapy. Stanford, CA: Stanford University Press.

Pennebaker, J. W., Booth, R. J., Boyd, R. L., \& Francis, M. E. (2015). Linguistic inquiry and word count: LIWC2015. Austin, TX: Pennebaker Conglomerates.

Pennebaker, J. W., Boyd, R. L., Jordan, K., \& Blackburn, K. (2015). The development and psychometric properties of LIWC2015. Austin, TX: Pennebaker Conglomerates.

Pennebaker, J. W., Chung, C. K., Frazee, J., Lavergne, G. M., \& Beaver, D. I. (2014). When small words foretell academic success: The case of college admissions essays. PloS One, 9, e115844.

https://doi.org/10.1371/journal.pone.0115844

Porter, J., \& Jick, H. (1980). Addiction rare in patients treated with narcotics. The New England Journal of Medicine, 302, 123. https://doi.org/10.1056/nejm198001103020221

Project MATCH Research Group. (1997). Matching alcoholism treatments to client heterogeneity. Journal of Studies on Alcohol, 58, 7-29. https://doi.org/10.15288/jsa.1997.58.7

Project MATCH Research Group. (1998). Matching alcoholism treatments to client heterogeneity: Project MATCH three-year drinking outcomes. Alcoholism: Clinical and Experimental Research, 22, 13001311. https://doi.org/10.1097/00000374-199809000-00016

Scholl, L., Seth, P., Kariisa, M., Wilson, N., \& Baldwin, G. (2019). Drug and opiod-involved overdose deaths - United States, 2013-2017. MMWR: Morbidity \& Mortality Weekly Report, 67(5152), 14191427. https://doi-org/10.15585/mmwr.mm675152e1

Seih, Y. T., Lin, Y. C., Huang, C. L., Peng, C. W., \& Huang, S. P. (2008). The benefits of psychological displacement in diary writing when 
using different pronouns. British Journal of Health Psychology, 13, 39-41. https://doi.org/10.1348/135910707x250875

Serafini, K., Malin-Mayor, B., Nich, C., Hunkele, K., \& Carroll, K. M. (2016). Psychometric properties of the Positive and Negative Affect Schedule (PANAS) in a heterogeneous sample of substance users. The American Journal of Drug and Alcohol Abuse, 42, 203-212. https://doi.org/10.3109/00952990.2015.1133632

Seth, P., Rudd, R. A., Noonan, R. K., \& Haegerich, T. M. (2018).

Quantifying the epidemic of prescription opioid overdose deaths. American Journal of Public Health, 108, 500-502. https://doi.org/10.2105/AJPH.2017.304265

Singer, J. B., \& Greeno, C. M. (2013). Case study: When Bambi meets Godzilla: A practitioner's experience adopting and implementing a manualized treatment in a community mental health setting. Best Practice in Mental Health, 9, 99-115.

Sutton, J. (2017). James Pennebaker "Real things are just endlessly fascinating." The Psychologist, 30, 64-67.

Tonigan, J. S., Connors, G. J., \& Miller, W. R. (2003). Participation and involvement in Alcoholics Anonymous. In T. F. Babor \& F. K. del Boca (Eds.), Treatment matching in Alcoholism (pp. 184-204). New York, NY: Cambridge University Press.

Vaillant, G. (2008). Spiritual evolution: A scientific defense of faith. New York, NY: Broadway Books.

Weisser, M. (2016). Practical corpus linguistics: An introduction to corpusbased language analysis. Chichester, England: Wiley Blackwell.

White, W. L. (1998). Slaying the dragon: The history of addiction treatment and recovery in America. Normal, IL: Chestnut Health Systems.

White, W. L. (2011). Wounded healers in recovery. Alcoholism Treatment Quarterly, 29, 99-102. https://doi.org/10.1080/07347324.2011.538321

Wilson, A. (2013). Embracing Bayes factors for key item analysis in corpus linguistics. In M. Biewwanger \& A. Koll-Stobbe (Eds.), New approaches to the study of linguistic variability (pp. 3-11). Frankfurt, Germany: Peter Lang.

Wilson, W. (2001). Alcoholics Anonymous: The story of how many thousands of men and women have recovered from alcoholism. New York, NY: Alcoholics Anonymous World Services. 
Wolpe, J. (1958). Psychotherapy by reciprocal inhibition. Stanford, CA: Stanford University Press.

Zemore, S. E. (2017). Implications for future research on drivers of change and alternatives to Alcoholics Anonymous. Addiction, 112, 940-942. https://doi.org/10.1111/add.13728

Table 1

Results for Broad Psycholinguistic, Linguistic, Psychological, and Physical Processes

\begin{tabular}{lllllll}
\hline Category & Process & TSF \% & MET \% & CBT \% & LL & BIC \\
\hline Analytic & Broad & 90.12 & 84.46 & 88.93 & $50.95^{* *}$ & Very Strong \\
Clout & Broad & 70.34 & 72.05 & 69.83 & $9.12^{* *}$ & Very Strong \\
Authentic & Broad & 16.17 & 25.99 & 24.21 & $741.86^{* *}$ & Very Strong \\
Tone & Broad & 27.61 & 35.05 & 26.35 & $350.33^{* *}$ & Very Strong \\
$1^{\text {st }}$ person sing. & Linguistic & 0.20 & 0.90 & 0.87 & $171.02^{* *}$ & Very Strong \\
$3^{\text {rd }}$ person sing. & Linguistic & 0.24 & 0.20 & 0.12 & $11.67^{* *}$ & Very Strong \\
$2^{\text {nd }}$ person & Linguistic & 0.89 & 2.48 & 1.79 & $217.74^{* *}$ & Very Strong \\
$3^{\text {rd }}$ person pl. & Linguistic & 1.46 & 0.54 & 1.18 & $114.46^{* *}$ & Very Strong \\
Negemo & Psychological & 2.38 & 1.98 & 2.46 & $14.21^{* *}$ & Strong \\
Male & Physical & 0.27 & 0.14 & 0.07 & $36.71^{* *}$ & Very Strong \\
Bio & Physical & 4.29 & 2.75 & 3.18 & $99.68^{* *}$ & Very Strong \\
\hline
\end{tabular}

${ }^{*} p<0.05,{ }^{* *} p<0.01$ 
Table 2

Post Hoc Results for Broad Psycholinguistic, Linguistic, Psychological, and Physical Processes

\begin{tabular}{|c|c|c|c|}
\hline Category & Corpus & $L L$ & $\mathrm{BIC}$ \\
\hline Analytic & TSF & $23.18^{* *}$ & 11.89 \\
\hline Analytic & MET & $48.69^{* *}$ & 37.4 \\
\hline Clout & MET & $8.59^{* *}$ & -2.7 \\
\hline Authentic & $\mathrm{TSF}$ & $726.62^{* *}$ & 715.33 \\
\hline Authentic & MET & $278.91^{* *}$ & 267.62 \\
\hline Authentic & CBT & $125.37^{* *}$ & 114.08 \\
\hline Tone & $\mathrm{TSF}$ & $51.14^{* *}$ & 39.85 \\
\hline Tone & MET & $341.94^{* *}$ & 330.65 \\
\hline Tone & $\mathrm{CBT}$ & $115.42^{* *}$ & 104.13 \\
\hline $1^{\text {st }}$ person sing. & TSF & $170.9^{* *}$ & 159.61 \\
\hline $1^{\text {st }}$ person sing. & MET & $38.94^{* *}$ & 27.65 \\
\hline $1^{\text {st }}$ person sing. & $\mathrm{CBT}$ & $38.91^{* *}$ & 27.62 \\
\hline $3^{\text {rd }}$ person sing. & $\mathrm{CBT}$ & $10.71^{* *}$ & -0.58 \\
\hline $2^{\text {nd }}$ person & $\mathrm{TSF}$ & $190.64^{* *}$ & 179.35 \\
\hline $2^{\text {nd }}$ person & MET & $128.79^{* *}$ & 117.49 \\
\hline $3^{\text {rd }}$ person pl. & $\mathrm{TSF}$ & $56.16^{* *}$ & 44.87 \\
\hline $3^{\text {rd }}$ person $\mathrm{pl}$. & MET & $106^{* *}$ & 94.71 \\
\hline Negemo & MET & $13.83^{* *}$ & 2.54 \\
\hline Male & TSF & $30.93^{* *}$ & 19.64 \\
\hline Male & $\mathrm{CBT}$ & $25.86^{* *}$ & 14.56 \\
\hline Bio & $\mathrm{TSF}$ & $92.17^{* *}$ & 80.88 \\
\hline Bio & MET & $52.68^{* *}$ & 41.39 \\
\hline Bio & $\mathrm{CBT}$ & $11.29 * *$ & 0 \\
\hline
\end{tabular}

